\title{
A produção de conhecimento e saberes do/a professor/a-pesquisador/a
}

\section{The researcher-teacher's knowledge and learning production}

\author{
Renata Barrichelo Cunha* \\ Guilherme do Val Toledo Prado**
}

\begin{abstract}
RESUMO
A discussão sobre a produção de conhecimentos e saberes do/a professor/a-pesquisador/a orienta parte das discussões do Grupo de Estudos e Pesquisas em Educação Continuada (Gepec), na Unicamp. As produções organizadas por Geraldi, Fiorentini e Pereira (2000), Cunha e Prado (2005) e a tese de Mota (2005), no diálogo com Severino (2002), Luna (2002), Lüdke (2001, 2004), Fiorentini (2004), entre outros autores, desencadearam a problematização acerca da legitimidade da pesquisa do/a professor/a. $\mathrm{O}$ encaminhamento da presente pesquisa, que buscou construir outros critérios para definir a pesquisa do/a professor/a-pesquisador/a em exercício na sala-de-aula, independentemente de estar envolvido/a em programas de pós-graduação, consultou trabalhos encaminhados por professores/as aos seminários organizados pelo Gepec - Seminários "Fala outra Escola" e "Seminário Produção de Conhecimentos, Saberes e Formação Docente" (Cole). Os trabalhos foram analisados a partir de critérios estabelecidos pelas reflexões do Gepec, confirmando a hipótese que antecipava a possibilidade de o/a professor/a construir e sistematizar conhecimentos e saberes a partir de sua experiência docente, narrando suas vivências, orientando-se por uma questão de pesquisa, transgredindo convenções teórico-metodológicas, produzindo novas compressões a respeito do trabalho pedagógico e mobilizando mudanças possíveis. Apesar das limitações impostas pelas condições de trabalho vividas pelos/as professores/as, os estudos revelam que a pesquisa do/a professor/a representa uma possibilidade concreta de construção de novas práticas e que seu olhar investigativo, além de iluminar

* Doutoranda no Gepec/FE/Unicamp.

** Pesquisador do Gepec/FE/ Unicamp.
\end{abstract}


essas mesmas práticas, também questiona teorias e produz conhecimentos e saberes caros ao universo da escola e da academia.

Palavras-chave: professor-pesquisador; saberes docentes; formação continuada.

\begin{abstract}
The discussion concerning the teacher-researcher's production of knowledge and cognizance is the axe of some discussions of the Research Group in Continuing Education (Gepec) at Unicamp. Productions organized by Geraldi, Fiorentini and Pereira (2000), Cunha and Prado (2005), as well as Mota's Ph.D (2005), in dialogue with Severino (2002), Luna (2002), Lüdke $(2001,2004)$ and Fiorentini (2004), among others, have promoted the problematization concerning the legitimacy of the teacher's research. The present research, which aims at constructing other criteria for defining the teacher-researcher's research in his-her teaching activity in classroom, independently from his-her being part of a Graduate Program, has consulted works from teachers who have sent them to the Gepec's seminars - Seminars "Another School Speaks" and "Seminar on the Production of Knowledge, Cognizance and Docent Formation (Cole). These works were analyzed by assuming criteria established by Gepec's reflections, confirming the hypothesis that had proposed the possibility of the teacher's constructing and systematizing knowledge and cognizance acquired from his-her docent experience, by narrating his-her experiences, by orienting him-herself by a research question, by transgressing theoretical-methodological patterns and by producing new understandings about his-her pedagogical work and thus mobilizing possible changes. In spite of the teacher's poor work conditions, this research reveals that the teacher's researches represent a concrete possibility for constructing new practices, since their questioning gaze is able not only to illuminate those practices but also to criticize theories and to produce important knowledge and cognizance for the school and the university.

Key-words: teacher-researcher; docent knowledge; continuing formation.
\end{abstract}




\section{Introdução}

O Grupo de Estudos e Pesquisas em Educação Continuada (Gepec) integra o Programa de Pós-Graduação da Unicamp e tem como perspectiva de formação docente a busca da compreensão dos saberes e práticas cotidianas dentro da complexidade da organização do trabalho pedagógico escolar. Nesse sentido, a pesquisa é tomada como eixo da formação continuada do/a professor/a e na (re)constituição do seu fazer docente.

Além de orientar os pós-graduandos e de organizar eventos internos, o Gepec promove cursos, palestras, seminários e encontros, que eventualmente contam com a participação de convidados internacionais. Nesse sentido, há que se destacar o Seminário "Fala (outra) escola", que ocorre a cada dois anos, com o propósito de socializar trabalhos realizados nas escolas, e destinado fundamentalmente aos educadores das redes públicas, e o Seminário "Produção de Conhecimentos, Saberes e Formação Docente", que acontece juntamente com o Congresso de Leitura (Cole).

O Seminário "Fala (outra) escola", em três edições (2000, 2002 e 2004), objetiva criar um espaço de diálogo de experiências e de socialização das produções dos profissionais da educação que vivem a escola como espaço-tempo de humanização das relações, de produção e trocas culturais e de produção de conhecimentos. É voltado para a comunidade escolar - pais, estudantes, professores, diretores, coordenadores e funcionários - que acredita nas possibilidades de construção de uma "escola outra": uma escola mais humana, mais viva, imersa nos conflitos cotidianos decorrentes das políticas impostas à comunidade escolar e voltada para a emergência dos fazeres e saberes de todas as pessoas da escola.

O Seminário "Produção de Conhecimentos, Saberes e Formação Docente" (2003 e 2005), que acontece no Cole, representa outro espaço importante de veiculação de produções dos diferentes sujeitos do processo educativo, que podem compartilhar suas experiências, sinalizando a singularidade e complexidade do trabalho pedagógico. O seminário aposta nas possibilidades de produzir múltiplas formas de organização do trabalho pedagógico e na fusão dos que pensam com os que fazem a educação, na expectativa de viabilizar uma "outra educação possível" para um "outro mundo possível". 


\section{A discussão sobre a pesquisa do/a professor/a-pesquisador/a}

A discussão sobre a pesquisa do/a professor/a-pesquisador/a e da pesquisa-ação orienta algumas discussões do Gepec, nomeadamente o conjunto de textos que compõem a obra organizada por Geraldi, Fiorentini e Pereira (2000) e Cunha e Prado (2005).

No primeiro trabalho, a pesquisa-ação do/a professor/a é valorizada por representar uma oportunidade para planejar, agir, observar e refletir sobre a prática, seu contexto e condições de trabalho, potencializando a produção de saberes que, dialogados e teorizados em grupo, dão legitimidade à autoria dos professores.

A discussão sobre a epistemologia da prática e a formação do profissional reflexivo, capaz de encontrar respostas aos dilemas que o exercício profissional impõe e que não estão prescritas nas teorias e técnicas, é amplamente debatida.

Em suas reflexões, Pereira (2000) aproxima os pensamentos de Stenhouse e Elliot, que lutaram por reconhecer no/a professor/a uma postura de produtor de conhecimentos sobre as situações vividas em sua prática docente, identificando uma compreensão comum a ambos de que a mudança curricular satisfatória depende do desenvolvimento das capacidades de auto-análise e reflexão dos professores. A pesquisa-ação é entendida, portanto, como um meio de apoio à aprendizagem profissional docente e formação do professor como pesquisador.

Segundo a autora, a pesquisa-ação aperfeiçoa a prática mediante o desenvolvimento das capacidades de discriminação e de juízo do profissional em situações concretas, complexas e humanas. O papel dos pesquisadores externos à instituição é o de facilitadores, estimulando a participação dos agentes internos nos processos de reflexão e possibilitando elaborações críticas às estruturas ideológicas que deformam suas próprias autocompreensões.

Zeichner é outro teórico que também reconhece que os professores produzem, em suas práticas, uma riqueza de conhecimentos que precisa ser considerada no processo de aperfeiçoamento do trabalho e da escola, e que justamente a prática reflexiva pode ampliar a compreensão das dimensões sociais e políticas da educação (Dickel, 2000).

Geraldi, Messias e Guerra (2000), a partir de Zeichner e Liston, definem os professores-reflexivos como aqueles que: 
Examinam, esboçam hipóteses e tentam resolver os dilemas envolvidos em suas práticas de aula; são alertas a respeito das questões e assumem os valores que levam/carregam para o seu ensino; estão atentos para o contexto institucional e cultural no qual ensinam; tomam parte no desenvolvimento curricular e se envolvem efetivamente para a sua mudança; assumem a responsabilidade por seu desenvolvimento profissional; procuram trabalhar em grupos, pois é nesse espaço que vão se fortalecer para desenvolver seus trabalhos (p. 252-253).

Nessa perspectiva estudada pelos autores, o professor-reflexivo faz pesquisa-ação, experiência que repercute em três dimensões: a do desenvolvimento profissional, a da prática social e política e, por conseqüência, dá visibilidade ao conhecimento produzido pelos professores. Na pesquisa-ação, os professores pesquisam sobre a sua prática e sobre o contexto de seu trabalho e, refletindo sobre suas atividades, sobre o seu ensino e as condições sociais que o produzem, criam saberes denominados “teorias práticas do professor". Os critérios de legitimidade de uma pesquisa-ação desenvolvidos pelos professores, na concepção de Zeichner, estão relacionados à clareza das idéias, subjetividade e reflexão por meio do diálogo. Essa proposta da prática reflexiva é entendida como uma forma de reação ao tecnicismo e à concepção de professores como meros executores de ordens, além de romper com a tradição de que o conhecimento só é produzido na Academia. Seu argumento principal é que os professores elaboram teorias que sustentam a sua prática e constroem práticas que embasam teorias.

Discutindo as afinidades entre as idéias desses autores - as divergências existem, mas não constituem propósito de discussão deste texto -, uma questão merece destaque. Elliot, Stenhouse e Zeichner concordam que o professor produz conhecimentos enquanto reflete sobre o seu trabalho, mas depende, necessariamente, de um pesquisador acadêmico que oriente, estimule, nutra e coopere com ele nesse processo.

Tomemos o texto de Zeichner (2000) - "Para além da divisão entre professor-pesquisador e professor acadêmico" - como referência para essa discussão. Zeichner, quando se refere ao professor-pesquisador da sala de aula, situa-o na vida acadêmica, pois está na universidade, nos programas de mestrado e doutorado ou atuando em pesquisa colaborativa com outros professores acadêmicos que estão na escola fazendo suas investigações. Embora afirme a necessidade de eliminar a separação que atualmente se faz entre o mundo dos professores-pesquisadores e o mundo dos pesquisadores acadêmicos, define a 
contribuição dos acadêmicos como provedores de conhecimentos sobre métodos de pesquisa e fonte de assistência na análise e interpretação dos dados aos professores. Defende a relevância de tratar os produtos das investigações de iniciativa e interesse dos professores, mas os insere na academia, dependentes, portanto, de professores acadêmicos mais bem preparados. A hierarquia entre os professores continua sendo sustentada.

A crítica que faz aos acadêmicos nas universidades, que rejeitam a pesquisa dos professores por considerá-la trivial, ateórica e irrelevante para seus trabalhos, não a considerando como forma de produção de conhecimento e sim como forma de desenvolvimento profissional, não se sustenta quando ele mesmo subordina o conhecimento do professor à apreciação do acadêmico, na pesquisa colaborativa.

A partir desses trabalhos, os textos de Cunha e Prado (2005a, 2005b) ampliam algumas discussões, problematizando se o/a professor/a-pesquisador/a é tão-somente aquele/a que produz conhecimento sobre o seu trabalho, orientado por programas de pós-graduação, ou o/a professor/a da escola básica que interroga a sua prática, investiga, documenta o seu trabalho, analisa, faz leituras, dialoga e constrói uma forma de compreensão e interpretação da realidade. A pergunta que se colocam é: o professor que não está na universidade e que está na escola pode desenvolver pesquisa considerada "legítima"?

O próprio conceito de pesquisa passa a ser questionado. Na concepção de Severino (2002) e Luna (2002), a pesquisa é produção de conhecimento novo, e o pesquisador precisa ter um preparo teórico-metodológico que o qualifique. Nessa visão, a pesquisa demanda a superação da constatação de informações coletadas e condições estudadas, implica conferir generalidade aos resultados, o domínio de um referencial teórico-epistemológico da área. O professor da escola básica não é compreendido como sujeito preparado para esse tipo de pesquisa.

O trabalho de investigação de Lüdke (2001) é representativo para a compreensão das possibilidades e limitações do trabalho de pesquisa do/a professor/a na escola. Sua investigação apontou que, para o/a professor/a desenvolver um trabalho de pesquisa em sua escola, as condições, a estrutura e os recursos que o/a cercam (ou não) - contrato e regime de trabalho, remuneração, plano de carreira, infra-estrutura física, apoio financeiro (bolsas), aquisição de materiais de consumo/material permanente, remuneração de pessoal de apoio, financiamento para encontros científicos, etc. -, além da cultura da instituição escolar, são decisivos na consecução desse tipo de trabalho e determinam a qualidade e a produtividade das pesquisas. Interroga: o/a professor/a da escola básica tem essas condições? 
Em produção mais recente, Lüdke (2004) relata uma pesquisa complementar centrada nas opiniões dos formadores de professores/as sobre o papel da pesquisa e que tipo de pesquisa o/a professor/a da educação básica pode desenvolver. Entre os achados da pesquisa, destaca uma contradição importante para ser dimensionada. Os professores-formadores afirmavam reconhecer diferenças entre tipos de pesquisa, para diferentes níveis de ensino e finalidades, mas não aceitavam discriminação hierárquica entre elas, atribuindo o mesmo valor do ponto de vista da construção do conhecimento e da busca de soluções para os problemas enfrentados. Justificavam que a função da pesquisa era exatamente buscar conhecimentos que encaminhassem essas soluções, independentemente dos recursos metodológicos e teóricos empregados. Em contrapartida, distinguiam a pesquisa acadêmica da pesquisa do professor, entendendo que a pesquisa universitária, designada como acadêmica, estaria pautada pelo modelo científico, e a do professor estaria mais voltada para os aspectos de cunho prático e de caráter urgente, ligados ao dia-a-dia das escolas.

Entendemos que a concepção de pesquisa dos professores formadores, bem como de Severino (2002), Luna (2002) e Lüdke (2001), está comprometida com a racionalidade moderna e com uma forma de entender a ciência como conhecimento verdadeiro e distinto sobre o real.

Buscando construir outras possibilidades de se pensar a produção de pesquisa do/a professor/a na escola, outros diálogos fizeram-se necessários a partir de novas questões.

A primeira questão é: o/a professor/a pesquisa ou reflete sobre o seu trabalho na escola? Quando reflete sobre o seu trabalho, está fazendo pesquisa?

Fiorentini (2004) nos auxilia a compreender que pesquisar e refletir são realmente práticas distintas, porém complementares. A reflexão não é necessariamente pesquisa e ocupa-se da totalidade, procurando levar em conta várias dimensões e perspectivas. A investigação exige um processo reflexivo "especial", que demanda a delimitação de um problema, um foco determinado que possa ser estudado com mais profundidade. Segundo o autor, a reflexão é condição necessária para a pesquisa, que solicita ainda leitura, descrição do fenômeno educativo, certo distanciamento da ação e um tratamento interpretativo e analítico.

A segunda questão é: o professor produz conhecimentos ou saberes na sua pesquisa?

Mota (2005) é nossa interlocutora para estabelecer algumas distinções e nos fazer avançar. Em sua dissertação, a autora empreende uma extensiva consulta a filósofos e epistemólogos que a habilitam a diferenciar conhecimento e saber. 
Para Mota, o conhecimento é uma apropriação cognitiva de um determinado objeto externo: o sujeito obtém uma imagem cognitiva interna de uma realidade externa. O saber implica uma relação entre o sujeito, o conhecimento e seu contexto, ou seja, uma interação sujeito-mundo. Construir conhecimentos seria objetivar informações, dados, conceitos. Construir saberes seria movimentar esses conhecimentos no contexto de ação, reinventando-os, recriando-os e traduzindo-os, de acordo com as circunstâncias da situação. A leitura de seu material nos convence de que entendemos/experienciamos nossos trabalhos como professores/as destas duas formas: conhecendo e sabendo. Saber e conhecimento são vistos como formas de se relacionar, pensar e expressar a realidade.

Acreditamos que há professores/as que produzem conhecimentos e saberes pedagógicos na sua sala de aula e com seus pares na escola e não são professores/as-pesquisadores/as, a despeito de poderem produzir mais do que professores que escolhem intencionalmente ser pesquisadores/as. A diferença entre um/a professor/a que produz conhecimentos e saberes e mantém uma postura interessada e um/a professor/a-pesquisador/a é que o primeiro muitas vezes não sabe ou não quer manejar os instrumentos e sistematizar sua produção de forma que seu conhecimento possa ser reconhecido como pesquisa.

A pesquisa supõe uma intencionalidade, um sentido de direção, um objetivo que mobiliza a reflexão. A pesquisa, sendo intencional, partindo de uma intenção, é uma opção do/a professor/a. O/a professor/a reflete porque é característica da própria natureza humana; pesquisa se reconhece que isso é importante para seu desenvolvimento profissional e componente de sua docência ética.

Contextualizando melhor: conhecer (e mobilizar nosso saber!) a pesquisa dos/as professores/as envolvidos em cursos de pós-graduação, especialização e graduação ou pesquisar - sem vínculos acadêmicos que implicam investigação - a sua prática no cotidiano da escola pode revelar olhares e modos de aproximação e organização de experiências e idéias que podem completar-se, valorizando a multiplicidade de percursos e autorias. Reconhecer a pesquisa do professor, orientada por projetos de mestrado e doutorado, e a pesquisa do professor da escola básica, orientada pelas inquietações e complexidades do trabalho na sala de aula, como complementares pode indicar que a produção de conhecimentos e saberes é legítima tanto na academia como na escola, sem a preocupação com o qualificativo de mais ou menos "científica". Conhecer/saber e reconhecer a pesquisa do/a professor/a como ação constitutiva da própria atividade docente, como processo de construção de conhecimentos e saberes - percurso de autoria - e condição de desenvolvimento profissional, 
com vistas à inovação e mudança da sua prática pedagógica, significa investilo de potencial reflexivo, transformador e emancipador.

A pesquisa do/a professor/a como exercício de formação, compartilhada no cotidiano da escola, no contexto de um trabalho coletivo docente, passa a ser o objeto de nossa reflexão e de nossa pesquisa, apresentadas a seguir.

\section{A pesquisa sobre a pesquisa do/a professor/a-pesquisador/a}

No decorrer dos diálogos com autores convidados para a interlocução e a partir de nossa experiência de leitura e análise dos trabalhos enviados aos seminários organizados pelo Gepec - Seminário "Fala (outra) escola" e Seminário "Produção de Conhecimentos, Saberes e Formação Docente" -, fortalecemos nossa convicção de que o/a professor/a-pesquisador/a não precisa estar necessariamente vinculado/a a programas de pós-graduação para produzir pesquisa. $\mathrm{O} / \mathrm{a}$ professor/a, no cotidiano da escola, compromissado com a sistematização de seus conhecimentos e acionando saberes, produzindo novas relações e mobilizando mudanças, pode ser reconhecido como professor/a-pesquisador/a.

Critérios precisam ser definidos, como fez Zeichner (apud Geraldi; Messias; Guerra, 2000), que elegeu a clareza das idéias, a subjetividade e a reflexão por meio do diálogo.

A partir de nossas análises e consulta aos textos, entendemos que, uma vez que o/a professor/a: toma o seu trabalho como espaço-tempo de produção de conhecimentos e saberes; orienta uma questão relevante para o seu trabalho na escola; organiza informações, interroga e busca respostas; sistematiza e registra suas análises e reflexões; reorienta o seu trabalho e encaminha outras (e novas) questões e socializa sua produção com outros parceiros, ele faz pesquisa.

Outra condição fundamental se faz necessária para que se constitua professor/a-pesquisador/a empenhado/a na construção de conhecimentos e saberes a respeito da sala de aula, do cotidiano da escola, dos seus alunos, de si mesmo: dialogar. Dialogar com autores e colegas, estabelecendo uma parceria que auxilie na fundamentação do próprio trabalho e em uma compreensão crítica de seu modo de produção. Diálogo constitutivo de si mesmo e do outro - seus colegas, alunos, professores acadêmicos, teóricos -, e que possibilita a emergência de nossas contra-palavras às suas palavras (BAKHTIN, 1999). 
Diante do conjunto de textos de professores/as que circularam nos seminários destacados, procedemos à leitura e análise das produções, tomando por base esses critérios. Não tivemos nenhuma preocupação de análise quantitativa, contabilizando o número de textos, temas, representatividade, organizando um porcentual final. Nosso objetivo foi tão-somente analisar nossa hipótese de que é possível ao professor de qualquer nível de ensino produzir pesquisa sobre a sala de aula, sobre a escola, sobre o seu trabalho.

Do material de pesquisa que estamos encaminhando para publicação (Cunha; Prado, 2005), extraímos uma amostra extremamente significativa que confirma nossa convicção de que é possível associar pesquisa e docência. Essas pesquisas constroem e reconstroem conhecimentos e saberes, atribuindo sentido e ressignificando a prática, num movimento que proporciona realização pessoal e desenvolvimento profissional.

Elas estão apresentadas de forma resumida, na expectativa de que inspirem outros/as professores/as a empreender essa experiência de pesquisa.

Cunha (2005), em Lembranças de escola na formação inicial de professores, narra a investigação de uma professora iniciante no ensino superior, inquieta com a postura de desinteresse pelo conhecimento por parte de suas alunas, futuras professoras. Instigada pela dúvida de que tipo de experiência com o conhecimento e estudo suas alunas experimentaram na escola básica, pesquisa as lembranças significativas dos tempos de escola e as repercussões no curso de formação de professoras, tentando compreender a relação conhecimento-aluna e sua responsabilidade como formadora em promover o desejo de aprender e ensinar.

Em Encaminhar: mostrar o caminho. Qual caminho? Há tantos jeitos diferentes de caminhar..., Guadagnim (2005) reflete sobre sua experiência como professora e diretora de uma escola pública municipal de Educação Infantil e a prática comum de encaminhamento de crianças para a sala especial. Com a responsabilidade de produzir um artigo que finalizasse seu curso de especialização em Educação Especial, propõe-se a rever suas crenças e seus conceitos, elaborando uma pesquisa que atualiza seus conhecimentos e investiga a instituição que recebe os encaminhamentos dos/as professores/as, avaliando e definindo o tipo de educação adequada para cada criança. Sua discussão informa as entrevistas feitas na instituição, problematiza os critérios de "classificação" das crianças portadoras de necessidades especiais, dialoga com autores que se ocupam das questões da formação de professores/as, apontando os caminhos e des-caminhos dessa prática de exclusão da diferença. Faz um exercício de metacognição do próprio texto, revendo os critérios de pesquisa implicados na sua produção, que a definem - com satisfação - como professora-pesquisadora. 
Autora de Projeto de trabalho que foi virando um projeto de pesquisa, Theodoro (2005) apresenta-se como uma professora empenhada em provocar o interesse de seus alunos pela leitura. Nesse contexto, em função de questões que demandaram investigações, realizou uma pesquisa com alunos de $6^{\mathrm{a}}$ série no que se refere às leituras sugeridas e livres que os alunos apreciavam e as aprendizagens nas rodas de leitura. A pesquisa alimenta a construção de um projeto de atividades, e as próprias atividades e dinâmicas informam sobre sua pesquisa, um exercício que demonstra como o fazer docente é fonte de produção de conhecimento e como a pesquisa mobiliza saberes que alimentam o ensino.

Almeida (2005), em Construção da ponte entre as intenções da professora e a aprendizagem dos alunos: relato de uma experiência de pesquisa que buscava a aproximação entre esses dois territórios, aborda o trabalho de pesquisa desenvolvido com grupos de alunos do Ensino Médio na disciplina de Filosofia, investigando os conceitos, representações e expectativas a respeito da disciplina. A pesquisa buscou encontrar respostas que possibilitassem a construção de seu programa de trabalho, mas investiu, sobretudo, na formação de um ambiente de trabalho que valorizasse o respeito e a diversidade. A professora personalizou feedbacks aos alunos, analisou seus dados em contextos amplos e destacou a importância da relação entre professor e alunos, comprometidos efetivamente em lidar com a diferença na sala de aula.

Por fim, Aprender a ensinar: uma lição de todo dia, de Barros (2005), lembra-nos do encanto de aprender e ensinar e aprender a ensinar, revelando a trajetória de uma professora alfabetizadora que busca construir uma prática consistente que considere os conhecimentos e saberes das crianças e as características dos conteúdos trabalhados com elas. Nessa busca pela construção de um conhecimento didático que lhe permitisse mediar o uso significativo da leitura e da escrita na escola, a professora encontrou seu modo particular de pesquisa - registros, análises, sistematização de princípios e "lições" - e definiu seus interlocutores/parceiros: alunos, pais, estagiários, professores, colegas e teóricos. Sua hipótese de pesquisa - como ajustar a proposta pedagógica às necessidades e potencialidades de aprendizagem das crianças - e sua questão orientadora é recorrente diante de todas as crianças que chegam à escola em todos os começos de anos letivos. Embora sua "pergunta" seja sempre a mesma, ela é nova a cada vez, jamais se esgota. Tomando como ponto de partida os sujeitos reais aos quais a sua prática pedagógica está destinada, a autora é obrigada a (re)construir continuamente novas configurações de pesquisa, transformando sua velha e conhecida pergunta numa nova pergunta - pelo menos parcialmente - sem resposta e, portanto, sempre nova. 


\section{Considerações finais}

Defender a idéia de que o/a professor/a pode reconhecer-se autor/a de uma pesquisa não é difícil se o/a reconhecemos como profissional portador de conhecimentos e saberes construídos em múltiplas instâncias de formação e em várias experiências profissionais.

Por manter um olhar investigativo para o seu trabalho no cotidiano da escola, sistematizar suas reflexões e dialogar com autores e pares, o/a professor/a assume a pesquisa como formação continuada e permanente e também como possibilidade de desenvolvimento profissional.

As professoras identificadas neste trabalho como professoras-pesquisadoras atuam da Educação Infantil ao Ensino Superior e tomam o próprio trabalho na escola como fonte de conhecimento que se traduz em saber, pois partem e retornam ao seu contexto: o próprio trabalho docente.

Esses trabalhos nos possibilitam reconhecer que: a experiência docente é riquíssima para a produção de conhecimentos e saberes sobre a organização do trabalho pedagógico; as narrativas escritas das vivências dos/as professores/as são documentos imprescindíveis para se conhecer a escola "por dentro" e constituem oportunidade de reflexão do/a professor/a, quiçá de investigação; as transgressões metodológicas das pesquisas dos/as professores/as-pesquisadores/as exigem o reconhecimento de que a pesquisa se dá por diversos caminhos.

Apesar das limitações impostas pelas condições de trabalho vividas pelos/as professores/as, as pesquisas revelam ainda que a pesquisa do/a professor/a representa uma possibilidade concreta de construção de novas práticas e que seu olhar investigativo, além de iluminar essas mesmas práticas, também questiona teorias e produz conhecimentos e saberes caros ao universo da escola e da academia. 


\section{REFERÊNCIAS}

ALMEIDA, A. M. C. F. Construção da ponte entre as intenções da professora e a aprendizagem dos alunos: relato de uma experiência de pesquisa que buscava a aproximação entre esses dois territórios. In: CUNHA, R. B.; PRADO, G. V. T. Percursos de autoria: exercícios de pesquisa. Campinas: Gepec/FE/Unicamp, 2005.

BAKHTIN, M. Marxismo e filosofia da linguagem: problemas fundamentais do método sociológico na ciência da linguagem. São Paulo: Hucitec, 1999. 196 p.

BARROS, R. M. Aprender a ensinar: uma lição de todo dia. In: CUNHA, R. B.; PRADO, G. V. T. Percursos de autoria: exercícios de pesquisa. Campinas: Gepec/ FE/Unicamp, 2005.

CAMPOS, S.; PESSOA, V. I. F. Discutindo a formação de professoras e de professores com Donald Schön. In: GERALDI, C. M. G.; FIORENTINI, D.; PEREIRA, E. M. A. (Orgs.). Cartografias do trabalho docente: professor(a)-pesquisador(a). 1. ed. Campinas: Mercado de Letras, 1998. p. 183-206.

CUNHA, R. B. Lembranças de escola na formação de professores. In: CUNHA, R. B.; PRADO, G. V. T. Percursos de autoria: exercícios de pesquisa. Campinas: Gepec/FE/Unicamp, 2005.

CUNHA, R. B.; PRADO, G. V. T. Percursos de autoria: exercícios de pesquisa. Campinas: Gepec/FE/Unicamp, 2005.

FIORENTINI, D. A didática e a prática de ensino mediadas pela investigação sobre a prática. In: ROMANOWSKI, J. P.; MARTINS, P. L. O.; JUNQUEIRA, S. R. (Orgs.). Conhecimento local e conhecimento universal: pesquisa, didática e ação docente. v. 1. Curitiba: Champagnat, 2004. p. 243-258.

GERALDI, C. M. G.; FIORENTINI, D.; PEREIRA, E. M. A. (Orgs.). Cartografias do trabalho docente: professor(a)-pesquisador(a). 1. ed. Campinas, SP: Mercado de Letras, $1998.335 \mathrm{p}$.

GERALDI, C. M. G.; MESSIAIS, M. G. M.; GUERRA, M. D. S. Refletindo com Zeichner: um encontro orientado por preocupações políticas, teóricas e epistemológicas. In: GERALDI, C. M. G.; FIORENTINI, D.; PEREIRA, E. M. A. (Orgs.). Cartografias do trabalho docente: professor(a)-pesquisador(a). 1. ed. Campinas, SP: Mercado de Letras, 1998. p. 237-276.

GUADAGNIM, V. C. Encaminhar: mostrar o caminho. Qual caminho? Há tantos jeitos diferentes de caminhar... In: CUNHA, R. B.; PRADO, G. V. T. Percursos de autoria: exercícios de pesquisa. Campinas: Gepec/FE/Unicamp, 2005. 
MOTA, E. A. D. Saberes e conhecimentos docentes: experiências da formação e experiências da profissão. Dissertação (Mestrado em Educação) - Faculdade de Educação, Universidade de Campinas, Campinas, 2005.

LÜDKE, M. O professor e a pesquisa. 2. ed. Campinas: Papirus, 2003. 112 p.

. Investigando sobre o professor e a pesquisa. In: ROMANOWSKI, J. P.; MARTINS, P. L. O.; JUNQUEIRA, S. R. (Orgs.). Conhecimento local e conhecimento universal: pesquisa, didática e ação docente. v. 1. Curitiba: Champagnat, 2004. p. 181-192.

LUNA, S. V. Planejamento de pesquisa: uma introdução. 7. ed. São Paulo: Educ, 2002. $108 \mathrm{p}$.

PEREIRA, E. M. Professor como pesquisador: o enfoque da pesquisa-ação na prática docente. In: GERALDI, C. M. G.; FIORENTINI, D.; PEREIRA, E. M. A. (Orgs.). Cartografias do trabalho docente: professor(a)-pesquisador(a). Campinas: Mercado de Letras, 1998. p. 153-182.

SCHÖN, John. Educando o profissional reflexivo: um novo design para o ensino e a aprendizagem. Porto Alegre: Artes Médicas, 2000. 256 p.

SEVERINO, A. J. Pós-graduação e pesquisa: o processo de produção e de sistematização do conhecimento no campo educacional. In: BIANCHETTI, L.; MACHADO, A. M. N. (Orgs.). A bússola do escrever: desafios e estratégias na orientação de teses e dissertações. 1. ed. Florianópolis: UFSC; São Paulo: Cortez, 2002. p. 67-88.

THEODORO, E. C. Projeto de trabalho que foi virando um projeto de pesquisa. In: CUNHA, R. B.; PRADO, G. V. T. Percursos de autoria: exercícios de pesquisa. Campinas: Alínea, 2007.

ZEICHNER, K. M. Para além da divisão entre professor-pesquisador e pesquisador acadêmico. In: GERALDI, C. M. G.; FIORENTINI, D.; PEREIRA, E. M. A. (Orgs.). Cartografias do trabalho docente: professor(a)-pesquisador(a). 1. ed. Campinas: Mercado de Letras, 1998. p. 207-236.

Texto recebido em 25 set. 2006 Texto aprovado em 19 mar. 2007 